intensity, although there was no further rise in temperature His mind did not become normal again for two days. He made His mind did not become normal again for two days. He made a rapid convalescence, but could not read for any length of last dose makes it, to my mind, certain that the influenza last dose makes it, to my mind

\section{CASE II.}

An elderly gentleman when first seen by me had been ill for a week with lethargy and bronchopneumonia. Micrococcus flavus, streptococci, and influenza bacilli were isolated from his sputum. He was exceedingly ill. The temperature was $102^{\circ}$, the pulse 90 to 100 . He was given at once a mixed antigen containing the above microbes pending the making of an autogenous antigen. The first dose was 11 million of each. There was a distinct improvement in twenty-four hours. Forty-eight was a distinct improvement in twenty-four hours. Forty-eight
hours after the first dose he was given $2 \frac{1}{3}$ million of each. The hours after the first dose he was given $2 \frac{1}{2}$ million of each. The next dose of his own antigens contained the same amount, and was given at a similar interval. The doses were continued up
to 20 million of each. All his symptoms and physical signs to 20 million of each. All his symptoms and physical signs valescent. He had no recognizable reactions after any dose, and made an uninterrupted recovery.

\section{CASE III.}

A woman, aged 22, became ill on December 25th, 1919. She felt very exhausted and sleepy, and in her sleep talked continuously, was very restless, and had jerking movements of thtinuously, was very restless, and had jerking movements of the limbs. She had been over, an week previously; she had had a previous nervous breakdown at the age of 16, when she suffered from undue sleepiness; for some time I thoughther symptoms could be similarly accounted for. When wakened from sleep she roused with a start, and told me she was very well; after a few minutes her eyes becam fixed, the eyelids closed, and she was asleep again, resuming the muttering and restless movements. She roused occasionally, and took food well. She was very constipated, but got
out of bed to urinate. At first she used to get up to sit by the fire, but always went to sleep in her chair.

After a time, since the sleepiness was getting worse rather than better and her memory for my previous day's visit was a complete blank, I determined to give her a dose of 21 million pure influen antigen. It was given at 10.30 a.m. on January 13th. She was asleep within five minutes of getting it. Two hours after she woke up very excited, nervous, and shivering, and as given 10 grams of aspirin. The unpleant symptoms and was givem passed off in an hour or two, and that evening she was much better, was able to talk rationally, and had no symptoms of lethargy. She slept much more normally that night and was much less restless in her sleep. When I saw her next morning she laughed and talked to me quite naturally. She improved steadily for some days, then began to get sleepy again and the other symptoms returned. On January 20 th I gave her $2 \frac{1}{2}$ million and she had the same symptoms as before but to a less extent, and next day was awake smiling and talking to me normally. Three days later, on January 23rd, I gave her $3 \frac{3}{4}$ million; she went to sleep after it, and remained lethargic that and the whole of the next day, being roused up to take food and then going to sleep again. Forty-eight hours after she was herself gain. Since then she has been given 5 million on February 2nd and 5 million on February 13 th; this dose was delayed by three rather severe uttacks of palpitation and then an attack three rather of colita. On February 16th February 20 th 10 million. On February 23 rd she was quite convalescent. I shall continue her doses up to 20 million as to leave a throughout.

CASE IV.

This was a minor case. The patient, a bank clerk aged 20 , had to leave her work early in December on account of feeling ill, having a severe headache and backache, feeling very drowsy and seeing double. When the acute symptoms had disappeared she went back to work, but could not do her work on account of not beingable to focus. I saw her on December 22nd; she was then fairly well, with the exception of the diplopia and being then fairly well, with the exception of the diplopia and being very easily tired. I assumed from her history that she was a case of influenza. I gave her three doses of pure influenza antigen, namely, 5 million, $7 \frac{1}{2}$ million, and 10 million, at weekly intervals. She had marked general and focal reactions, beginning a few hours after the first two inoculations, becoming so
drowsy that she had to go to bed, and slept without stirring. drowsy that she had to go to bed, and slept without stirring. The diplopia was intensitied the next day, but then gradually improved until the reaction after the second injection; she had much less reaction after the third, and then improved

I have found that pure influenza antigen rapidly relieves ther cases of post-influenzal debility.

No doubt those who do not believe in the specificity of antigen-therapy will question the diagnostic conclusions $I$ have drawn from these cases, and also my belief in the specific therapeutic results obtained. I believe that sucl results can only be obtained with a specific antigen or antigens, and think the test is just as specific and significant as the subcutaneous tuberculin test.

\section{APPENDICITIS WITHOUT PROTECTIVE S'IIFFENING OF THE ABDOMINAL WALL.}

By JOHN D. MALCOLM, F.R.C.S.EDIN., CONSULTING SURGEON, SAMARITAN FREE HOSPITAL, LONDON.

Protective contraction of the abdominal wall over the caecal region is a well known indication of appendicitis but its importance is sometimes exaggerated. Twice recently it has been suggested to me that appendicitis could not exist because of the absence of this sign. The following case is to the point:

On January 24th a lady, aged 23, being apparently quite well, was seized with intense abdominal pain about 3 p.m. At 5 p.m. Dr. J. A. Maclaren found a round .swelling in the appendix region. It was very tender, but the fingers could be pushed deeply into the tissues all round and close to it withou causing pain or muscular resistance. The temperature was $102^{\circ}$ F., the pulse 100 . A dose of castor oil was given, and two days later all swelling, pain and fever had gone. On January the caecal region. There was no resistance to palpation.

At the age of 3 months and again at 12 years this patient had severe illnesses affecting the abdomen. Occasional stitches in the side and indigestion, characterized chiefly by breathlessthe side and indigestion, characterized chiefly by breathlessness, had been increasingly troublesome within the last halfyear. Stone in the ureter was excluded by $x$-ra

When the abdomen was opened, the appendix, except about half an inch at its base, was firmly adherent in a peritoneal half an inch at its base, was firmly adherent in a peritoneal pouch behind the caecum. It measured $4 \frac{1}{2}$ in. by $\frac{1}{2}$ in. throughthickened and its canal containing a little soft faeces. It was removed and recovery was uncomplicated.

There is little doubt that this patient had her first attack of appendicitis in childhood. The absence of protective contraction of the muscles was due to the position of the appendix and to the fact that a spreading peritonitis was prevented by the aduesions, which had long existed. In such circumstances the danger is not so great as when the appendix lies free amongst the coils of small intestine. But in this case it would have been a serious mistake to have delayed surgical treatment. The operation was not easy, and it would have been much more difficult and dangerous had it become necessary during an acute inflammatory attack.

A dose of castor oil is sometimes the best treatment for an appendicitis, always provided that an immediate operation can be arranged if this method is not successful, and that the rapid and apparently complete cure which may be effected does not mislead the medical adviser.

\section{A NOTE ON ARTIFICIAL PNEUMOTHORAX,} With DEscription OF a NeW NeEDLE. BY

FREDERIC C. COLEY, M.D., PHYSICIAN TO THE NORTHERN COUNTIES HOSPITAL FOR DISRASES OF THE CHEST, AND TO THE BARRASFORD BANATORIUM.

I HAVE been using for many months a pneumothorax needle which has, I believe, several important practical advantages. The ordinary Saugman's needle with which I began to work has an obvious defect. It has no provision for excluding communication with the external air when the stopcock is opened to admit the stylet. This is the more objectionable because the stylet is required just when such communication might be most dangerous, namely, when oscillations of the manometer are absent or imperfect. If the stylet has been successful in clearing the needle and establishing free oscillations, it will be practically impossible to prevent some air from being sucked into the pleura while the stylet is being withdrawn, before the stopcock can be closed, and that air will not be aseptic. Dr. Clive Riviere obviates this difficulty by tying a piece of sheet india-rubber over. the open end of the instrument. I believe he uses this either with his own trocar and cannula in primary operations, or for an ordinary needle in doing " refills." I have secured the same object, I believe more effectually and simply, by attaching to the mount of the needle a little stuffing.box like that of a Potain's aspirator. But in Potain's instrument the stuffing. box simply plugs into the mount of the needle. This 